\title{
Endoscopic submucosal dissection in the stomach under equal multi-traction from four directions
}

Although endoscopic submucosal dissection (ESD) has become widespread because of its higher cure rate for nonmetastatic gastrointestinal tumors [1-3], it is technically challenging. Therefore, several traction techniques have been developed $[4,5]$. We report a case in which multi-traction was useful for gastric ESD. A 77-year-old man visited our hospital because of abdominal discomfort. Esophagogastroduodenoscopy revealed superficial gastric cancer at the greater curvature of the antrum ( $\triangleright$ Fig. $1 \mathbf{a}$ ), where endoscope instability is expected during ESD. ESD was performed using an IT knife-2 (Olympus, Tokyo, Japan) [3] under equal traction from four directions in order to secure the submucosal layer.

After circumferential mucosal incision and sufficient cutting of the submucosal layer, four-point traction was established using an SB clip (Sumitomo Bakelite Co., Ltd., Tokyo, Japan) and DT hood (Adachi Co., Ltd., Osaka, Japan) [5], which stores two elastic strings consisting of seven rings ( $\triangleright$ Fig. 2). The first ring of the first string was fixed to the opposite intact mucosa by the first clip through the endoscope. The second ring was fixed to the left anal edge of the lesion by the second clip. Next, the fifth ring was fixed to the right anal edge of the lesion by the third clip, and the sixth ring was fixed to the opposite intact mucosa by the fourth clip. Thus, two-point traction was created in a U-shaped manner ( Fig. 1 b). Next, two-point traction in the oral bilateral edge of the lesion was similarly created using the second string. After completing equal four-point traction from four directions ( $>$ Fig. $\mathbf{3}$ ), one-piece resection was performed under more effective traction and without adverse events ( Fig. 1 c, d,e, - Video 1). Histopathological findings included intramucosal well-differentiated adenocarcinoma with a negative cut margin.

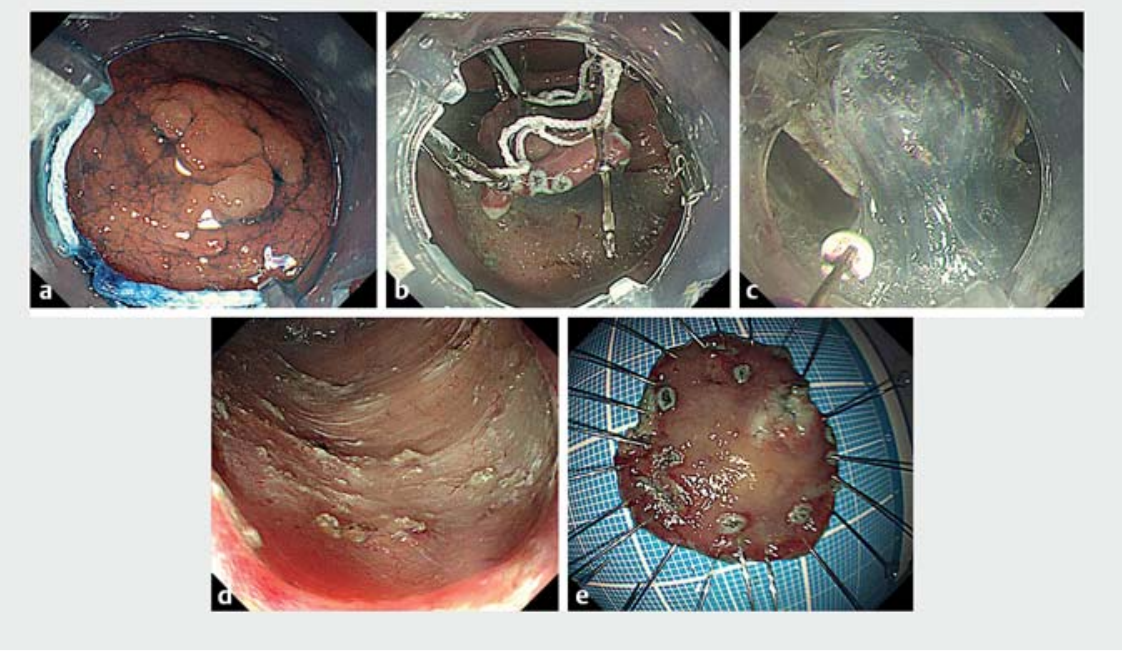

- Fig. 1 Endoscopic view. a The superficial gastric cancer at the greater curvature of the antrum before endoscopic submucosal dissection (ESD). b, c The lesion under four-point traction. d, e Post-ESD ulcer and resected specimen.
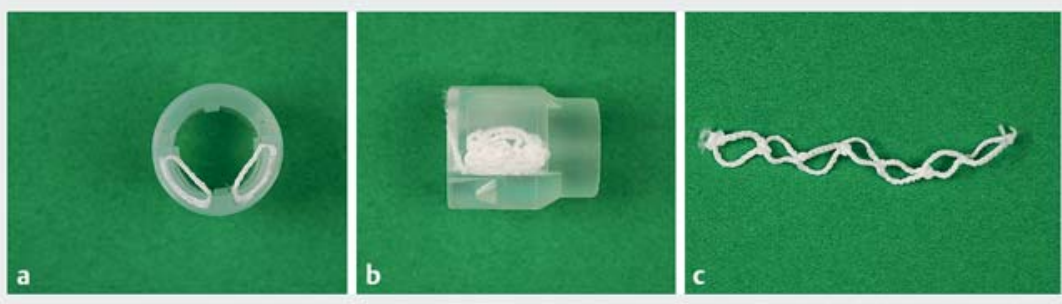

Fig. 2 The DT hood. a, b The device stores two strings in its side pockets for use in traction. c Each string consists of seven rings.

Four points of equal traction were established from four directions using the DT hood, which is useful for ESD of widespread superficial neoplasms.

Endoscopy_UCTN_Code_TTT_1AO_2AG

\section{Competing interests}

The authors declare that they have no conflict of interest.
The author

\section{Kinya Fujita}

Gastroenterology, Tsukazaki Hospital, Himeji City, Hyogo, Japan

\section{Corresponding author}

\section{Kinya Fujita, MD}

Gastroenterology, Tsukazaki Hospital, 68-1 Waku, Aboshiku, Himeji City, Hyogo Prefecture, 671-1227, Japan

kfujita1017@gmail.com 


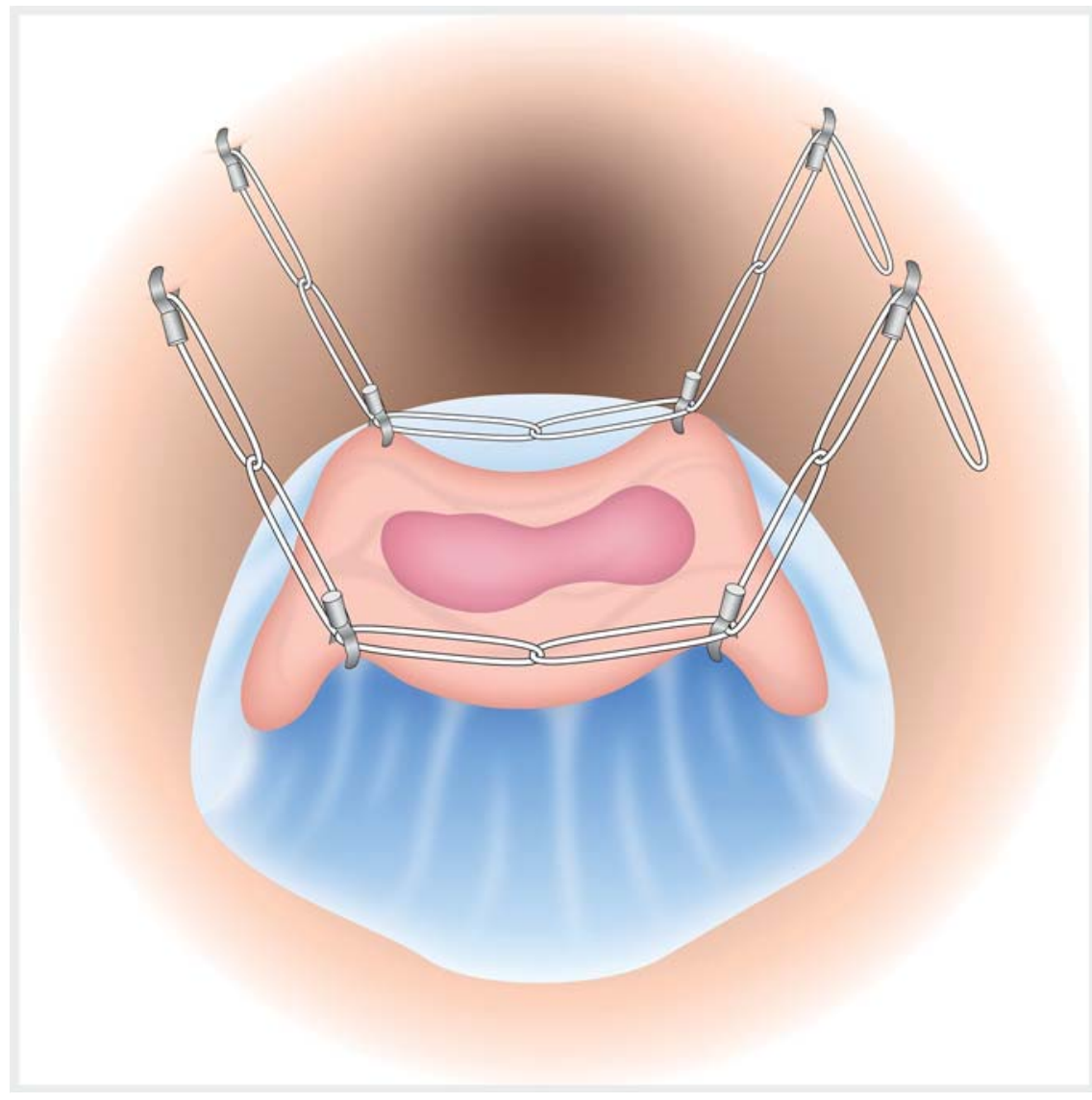

- Fig. 3 Schematic illustration of four-point traction.

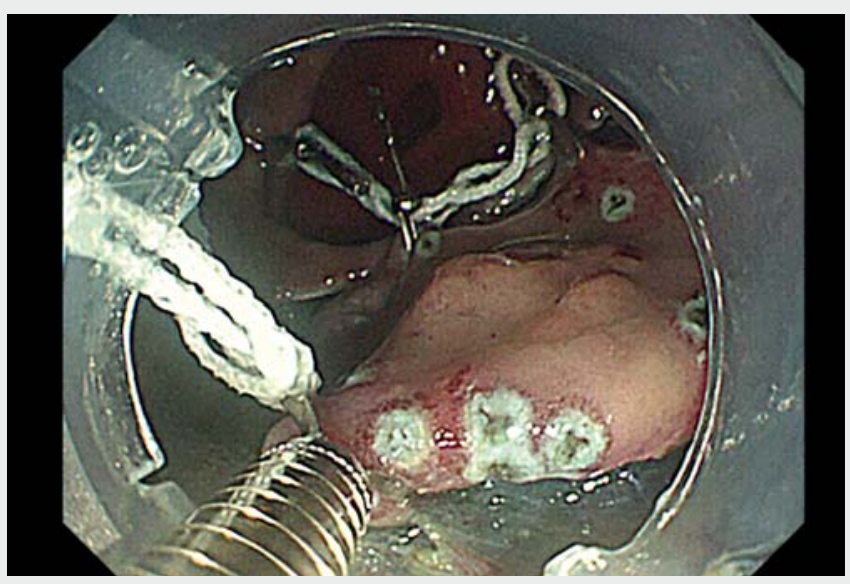

Video 1 We performed gastric endoscopic submucosal dissection (ESD) under equal four-point traction from four directions. Traction was created by endoclips and a DT hood, which facilitated safe ESD despite the difficulty of an unstable endoscope.
[1] Gotoda T, Yanagisawa A, Sasako M et al. Incidence of lymph node metastasis from early gastric cancer: estimation with a large number of cases at two large centers. Gastric Cancer 2000; 3: 219-225

[2] Gotoda T, Kondo H, Ono H et al. A new endoscopic mucosal resection procedure using an insulation-tipped electrosurgical knife for rectal flat lesions: report of two cases. Gastrointest Endosc 1999; 50: 560-563

[3] Ono H, Hasuike N, Inui T et al. Usefulness of a novel electrosurgical knife, the insulationtipped diathermic knife-2, for endoscopic submucosal dissection of early gastric cancer. Gastric Cancer 2008; 11: 47-52

[4] Saito Y, Emura F, Matsuda T et al. A new sinker-assisted endoscopic submucosal dissection for colorectal cancer. Gastrointest Endosc 2005; 62: 297-301

[5] Fujita K, Takeshita M, Moriyama E et al. Novel technique for endoscopic submucosal dissection using an elastic thread delivery hood. Endoscopy 2019; 12: E178-E180

\section{Bibliography}

Endoscopy 2022; 54: E552-E553

DOI 10.1055/a-1670-6947

ISSN 0013-726X

published online 19.11.2021

(c) 2021. Thieme. All rights reserved.

Georg Thieme Verlag KG, Rüdigerstraße 14, 70469 Stuttgart, Germany

\section{ENDOSCOPY E-VIDEOS \\ https:/|eref.thieme.de/e-videos}

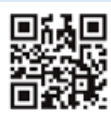

Endoscopy E-Videos is an open access online section, reporting on interesting cases and new techniques in gastroenterological endoscopy. All papers include a high quality video and all contributions are freely accessible online. Processing charges apply (currently EUR 375), discounts and wavers acc. to HINARI are available.

This section has its own submission website at https://mc.manuscriptcentral.com/e-videos 